\title{
Dioxin-like activities in serum across European and Inuit populations
}

\author{
Manhai Long1, Birgitte S Andersen ${ }^{1}$, Christian H Lindh², Lars Hagmar², \\ Aleksander Giwercman³, Gian-Carlo Manicardi4 ${ }^{4}$, Davide Bizzaro5, \\ Marcello Spanò ${ }^{6}$, Gunnar Toft 7 , Henning S Pedersen ${ }^{8}$, Valentyna Zvyezday9 \\ Jens Peter Bonde ${ }^{7}$ and Eva C Bonefeld-Jorgensen*1
}

\begin{abstract}
Address: ${ }^{1}$ Unit of Cellular \& Molecular Toxicology, Department of Environmental and Occupational Medicine, Institute of Public Health, University of Aarhus, Vennelyst Boulevard 6, DK-8000 Aarhus C, Denmark, ${ }^{2}$ Department of Occupational and Environmental Medicine and Psychiatric Epidemiology, University Hospital, SE-221 Lund, Sweden, ${ }^{3}$ Fertility Centre, Malmö University Hospital, Lund University, Malmö, SE205 02, Sweden, ${ }^{4}$ Laboratory of Genetics, Department of Agricultural Sciences, University of Modena and Reggio Emilia, Viele Kennedy 17 Reggio Emilia I-41100 Modena, Italy, ${ }^{5}$ Institute of Biology and Genetics, Politechnical University of Marche, Via Brecce Bianche 1-60131 Ancona, Italy, ${ }^{6}$ Section of Toxicology and Biomedical Sciences, BIOTEC-MED, ENEA Casaccia, Via Anguillarese 301, 00060 Rome, Italy, ${ }^{7}$ Department of Occupational Medicine, Aarhus University Hospital, Nørrebrogade 44, build. 2C, DK-8000 Aarhus C, Denmark, ${ }^{8}$ Center for Arctic Environmental Medicine, postbox 570DK-3900 Nuuk, Greenland, Denmark and '92aboratory of Human Reproduction, Kharkiv State Medical University, Klochkovskaya Street 156-A, room 14, 61145 Kharkiv, Ukraine

Email: Manhai Long - ml@mil.au.dk; Birgitte S Andersen - bsa@mil.au.dk; Christian H Lindh - christian.lindh@med.lu.se; Lars Hagmar - lars.hagmar@med.lu.se; Aleksander Giwercman - aleksander.giwercman@med.lu.se; Gian-

Carlo Manicardi - manicardi.giancarlo@unimore.it; Davide Bizzaro - d.bizzaro@univpm.it; Marcello Spanò - spanomrc@casaccia.enea.it; Gunnar Toft - gutof@as.aaa.dk; Henning S Pedersen - hsp@gh.gl; Valentyna Zvyezday - dimusic@ic.kharkov.ua;

Jens Peter Bonde - jpbon@as.aaa.dk; Eva C Bonefeld-Jorgensen* - ebj@mil.au.dk

* Corresponding author
\end{abstract}

This is an Open Access article distributed under the terms of the Creative Commons Attribution License (http://creativecommons.org/licenses/by/2.0), which permits unrestricted use, distribution, and reproduction in any medium, provided the original work is properly cited.

\footnotetext{
Abstract

Background: Persistent organic pollutants (POPs) such as polychlorinated dibenzo-p-dioxins/furans, polychlorinated biphenyls (PCBs) and organochlorine pesticides can cause a series of adverse effects on e.g. reproduction in animals and humans, many of which involve the aryl hydrocarbon receptor (AhR). The aim of the present study was to compare the integrated serum level of AhR mediated activity among European and Inuit populations, and evaluate whether the activity was associated to the selected POP markers, 2,2',4,4',5,5'-hexachlorobiphenyl (CB-I53) and I,I-dichloro-2,2-bis(Pchlorophenyl)-ethylene ( $\left.p, p^{\prime}-\mathrm{DDE}\right)$.

Methods: The study included 338 males from Greenland (Inuit's), Sweden, Warsaw (Poland) and Kharkiv (Ukraine). The AhR transactivity of serum extracts alone (AhRag) and competitive AhR activity (AhRcomp) upon co-exposure with 2,3,7,8-tetrachlorodibenzo-p-dioxin (TCDD) were determined in the lipophilic serum fraction containing the POPs using the AhR mediated luciferase reporter Hepal.I2cR cell assay.

Results: The European groups showed higher median level of AhR-TEQ (TCDD toxic equivalents) compared to the Inuit's, whereas higher incidence of Inuits sample further induced AhRcomp activity. Neither AhRag nor AhR-TEQ were correlated to CB-I53 or p, $p^{\prime}-\mathrm{DDE}$ for any of the study groups. Multiple regressions showed a significant heterogeneity of association between the CB-I53 and the AhRcomp across the study groups, and accordingly a negative association between AhRcomp and CB-I53 was found for the Kharkiv group.
} 
Conclusion: No consistent correlation between AhR activities and two POP markers was found. Although the difference of AhRag between European and Inuit men could not be explained by CB-I53 or p, $p^{\prime}$-DDE levels alone, we believe that the variation of AhR serum activity reflects different pattern of POP exposure, genetics and/or life style factors.

\section{Background}

The polychlorinated dibenzo- $p$-dioxins/furans (PCDDs/ PCDFs), polychlorinated biphenyls (PCBs) and organochlorine pesticides, such as 2,2-bis(p-chlorophenyl)1,1,1-trichloroethane (DDT), are prominent among the persistent organic pollutants (POPs). Owing to their negative effects on wildlife and human health, PCBs and DDT were restricted or totally banned in most countries during the 1970s. However, PCBs can still be released into the environment from poorly maintained hazardous waste site and illegal or improper dumping of PCB wastes like leaking from old electrical transformers, and DDT is still used in some developing countries [1]. Being resistant to both biotic and abiotic degradation, DDT (mainly as its major metabolite, 1,1-dichloro-2.2-bis (p-chlorophenyl)ethylene ( $p, p^{\prime}$-DDE) ) and PCBs bioaccumulate and magnify in animals and humans [2,3]. Residues have been detected in various food substances and in human adipose tissue, milk, and serum [1,4]. While PCBs and DDT contamination is ubiquitous globally, a high intake of fish and sea mammal food in the Arctic regions is associated with extraordinary high exposure $[5,6]$. Also Swedish fisherman's families of the Baltic Sea with a high consumption of herring and salmon being contaminated with POPs, constitute a highly exposed group [7,8]. For the general populations in Eastern Europe, the burden of POPs has been less systematically examined $[9,10]$.

It has been documented that exposure to POPs such as dioxins (e.g. 2,3,7,8-tetrachlorodibenzo-p-dioxin, TCDD) and dioxin-like compounds (DLCs) such as non-ortho and mono-ortho PCBs may cause a series of negative effects both in animal experiments and in human epidemiologic studies including carcinogenicity [11], immunotoxicity and adverse effects on reproductive, neurobehavioral [12]. The toxicity of dioxins and DLCs is mediated mainly through binding to the aryl hydrocarbon receptor (AhR), which is an intracellular ligand-dependent transcriptional factor expressed in most tissues of mammals [13]. Upon receptor-ligand binding and translocation to the nucleus, the complex with the AhR nuclear translocator binds to the DNA dioxin-responsive elements, causing induction of gene transcription, for instance, encoding for metabolic enzymes [14]. More recently, interference of POPs or their metabolites with hormone receptors has also been observed $[15,16]$. Previous studies demonstrated the presence of a two-way cross talk between the intracellular signalling pathways involving the estrogen- (ER), androgen-
(AR) and the Ah- receptor [17]. Several studies on wildlife and laboratory animals showed that exposure to PCBs and $p, p^{\prime}$-DDE can affect reproductive and endocrine functions $[5,18]$. However, human epidemiologic data are limited and major gaps in knowledge continue to preclude evidence based risk assessment.

Since dioxins and DLCs exist as complex mixtures of various congeners throughout the environment, the concept of TEQ (TCDD toxic equivalent) has been introduced to simplify risk assessment and regulatory control [3]. The classical TEQs are calculated by multiplying the concentration of individual PCDDs/PCDFs/PCBs by their respective Toxic Equivalency Factors (TEFs), which correspond to the relative potency of the congener to generate AhRmediated effects in relation to TCDD, the most potent AhR ligand. Previous studies emphasize that assessment of the toxicological potential of a chemical mixture is much more complex than can be deduced by a given calculated TEQ value $[5,19]$. There are several drawbacks using the TEF concept for risk assessment of mixtures of POPs such as expensive and time consuming gas chromatography mass spectrometry (GC-MS) determinations, small concentrations of individual congeners, presence of compounds not routinely measured or unknown substances with AhR affinity, the lack of TEF values for several POPs, and possible antagonistic or synergistic interactions between POPs [20-22]. Thus there is a need for an integrated risk assessment of dioxins and DLCs. The in vitro AhR mediated chemical activated luciferase gene expression (CALUX) bioassay has proven to be a quick and sensitive assay to detect the AhR mediated potential of pure chemicals [20-23], extracts of environmental and biological matrices and thus the integrated TEQ value (CALUXTEQ) of complex mixtures as found in sediment, pore water, bovine and human milk, human serum and follicular fluid [24].

This study was a part of the EU supported research project Inuedo [25] with the main objective to elucidate the fertility in European and Inuit groups with different intake of POPs $[26,27]$. The 2,2',4,4',5,5'-hexachlorobiphenyl (CB153) and $p, p^{\prime}$-DDE were selected as proxy biomarkers of POPs exposure because CB-153 generally correlates with serum total PCB concentration and chemical derived TEQ $[28,29]$, and $p, p^{\prime}$-DDE was considered as a relevant marker of POPs [30]. The specific aim of the present study was to compare the actual level of AhR mediated dioxin-like 
activity in the lipophilic serum fraction between European and Inuit study groups, and to evaluate whether the tested dioxin-like activity was correlated to CB-153 or $p, p^{\prime}$-DDE.

\section{Methods}

\section{I. Study groups and sampling}

The Inuedo source populations encompassed women and their male spouses who had antenatal care visits from May 2002 through February 2004 at the local hospitals in Greenland, Warsaw, Poland and Kharkiv, Ukraine [26]. An established cohort of Swedish fishermen was also included [31]. The study was approved by the local ethical committees representing all participating populations and all subjects signed an informed consent. The subjects of the present study were adult males randomly selected from the source populations. Demographic and lifestyle factors such as age, body mass index (BMI), alcohol consumption, intake of seafood, coffee and smoking habits were collected by questionnaires (Table 1) $[26,27]$.

This study included in total 338 blood samples taken from males from Greenland (75), Sweden (78), Warsaw (99) and Kharkiv (86). Venous blood samples were collected in $10 \mathrm{ml}$ vacuum tubes and after centrifugation the serum was transferred to Nunc tubes and stored at $-80^{\circ} \mathrm{C}$ until analyzed [27].

\section{2. Determination of CB-I53 and $p, p^{\prime}-D D E$ in serum}

Serum concentrations of CB-153 and $p, p^{\prime}$-DDE were determined using GC-MS after solid phase extraction and oncolumn degradation of lipids. CB-153 and $p, p^{\prime}$-DDE levels were adjusted for serum lipids analyzed by enzymatic methods $[27,31]$. Levels of detection, coefficients of variation (CV) and participation in quality control programs have been described in detail elsewhere [27]. All analysis of CB-153 and $p, p^{\prime}$-DDE were performed at the Department of Occupational and Environmental Medicine, University of Lund, Sweden.

\section{3. AhR-CALUX assay}

\section{3.I. Sample preparation}

The extraction of serum sample to obtain the fraction containing lipophilic POPs for AhR-CALUX activity measurements was performed at a certified laboratory, Le Centre de Toxicologie, Sainte Foy, Quebec, Canada. Serum samples $(2 \mathrm{ml})$ were mixed with an aqueous solution of ammonium sulfate and ethanol (1:1) and then extracted with hexane. Extracts were concentrated and cleaned by elution through two columns containing Florisil. The details of extraction has been described elsewhere [32]. The extracts dissolved in $500 \mu \mathrm{l}$ hexane were stored at $80^{\circ} \mathrm{C}$ until analyzed.

Table I: Characteristics of the men in the study groups

\begin{tabular}{|c|c|c|c|c|c|c|}
\hline & & Greenland $n=75$ & Warsaw $n=99$ & Sweden $n=78$ & Kharkiv $n=86$ & All $n=338$ \\
\hline \multirow[t]{2}{*}{ Age (years) } & median & 30 & 30 & 46 & 26 & 32 \\
\hline & $\min -\max$ & $23-47$ & $18-46$ & $24-67$ & $16-45$ & $16-67$ \\
\hline \multirow[t]{2}{*}{ BMI $\left(\mathrm{Kg} / \mathrm{m}^{2}\right)$} & median & 26 & 26 & 26 & 24 & 25 \\
\hline & $\min -\max$ & $19-38$ & $12-58$ & $22-37$ & $19-36$ & $12-58$ \\
\hline \multirow{2}{*}{$\begin{array}{l}\text { Alcohol (drink/ } \\
\text { week) }\end{array}$} & median & 2.0 & 3.5 & n.a & 2.5 & 3.00 \\
\hline & $\min -\max$ & $0-35$ & $0-30$ & & $0.2-15$ & $0-35$ \\
\hline Smoking (ever) & $\%$ & 87 & 49 & 40 & 82 & 68 \\
\hline \multirow{2}{*}{$\begin{array}{l}\text { Seafood (days/ } \\
\text { week) }\end{array}$} & median & 2.0 & 1.0 & n.a & 4.0 & 2.0 \\
\hline & $\min -\max$ & $0-9.0$ & $0-9.0$ & & $1.0-9.0$ & $0-9.0$ \\
\hline \multirow[t]{2}{*}{ Coffee (cups/day) } & median & 3.0 & 2.0 & n.a & 2.0 & 2.0 \\
\hline & $\min -\max$ & $0-20$ & $0-6.0$ & & I.0-7.0 & $0-20$ \\
\hline \multirow{2}{*}{$\begin{array}{l}\text { Total } \\
\text { testosterone } \\
(\mathrm{nmol} / \mathrm{l})\end{array}$} & median & 14 & 13 & 12 & 18 & 14 \\
\hline & $\min -\max$ & $3.2-75$ & $6.5-23$ & $4.2-28$ & $8.4-32$ & $3.2-32$ \\
\hline \multirow[t]{2}{*}{ Estradiol (nmol/l) } & median & 59 & 72 & 67 & 81 & 71 \\
\hline & $\min -\max$ & $31-88$ & $45-296$ & $25-155$ & $33-144$ & $25-296$ \\
\hline
\end{tabular}




\subsubsection{Dissolving of samples}

The serum extracts were thawed and evaporated to near dryness at $30^{\circ} \mathrm{C}$ under the gentle stream of nitrogen. The sample solvent, $10 \mu \mathrm{l}$ DMSO: $\mathrm{H}_{2} \mathrm{O}(5: 5, \mathrm{v} / \mathrm{v})$, was added to each sample vial and stored overnight at room temperature. After giving the samples a quick spin (1000 rpm, 25 sec.), $500 \mu \mathrm{l} \alpha$-minimal essential medium ( $\alpha$-MEM, GibcoBRL, UK) was added, mixed completely and transferred to two new test tubes $(250 \mu \mathrm{l} /$ tube $)$ each containing 417 $\mu$ supplemented $\alpha$-MEM ( $\alpha$-MEM plus $10 \%$ fetal calf serum (FCS, GibcoBRL, UK), $64 \mu \mathrm{g} / \mathrm{ml}$ garamycin (Schering-Plough, Brussels, Belgium)) with or without the 60 pM $\left(E_{50}\right)$ (see 2.3.3) TCDD (98\%, Cambridge Isotopes Laboratories Inc., USA), respectively. The final serum extract was equal to $150 \mu \mathrm{l}$ serum per well (96- well plate) which was shown to be in the linear range of the AhR mediated luciferease activity (Bonefeld Jorgensen and Long, manuscript in prep.). All the processes were protected from light.

\subsubsection{AhR-CALUX bioassay}

The stable transfected mouse hepatoma cell line Hepa1.12cR carrying the AhR-luciferase reporter gene (kindly provided by M.S. Denison (University of California, USA)), induces luciferase in an AhR-, time- and dosedependent manner [23]. In each independent experiment, a dose-response of TCDD (dissolved in DMSO and subsequently diluted in the supplemented $\alpha$-MEM) was performed at concentrations ranging from $2 \times 10^{-12}$ to $5 \times 10^{-}$ ${ }^{9} \mathrm{M}$ (see additional file 1: TCDD dose-response curve for AhR mediated luciferase activity). The maximum effect concentration was $1000 \mathrm{pM}$, and the half maximum effect concentration $\left(\mathrm{EC}_{50(\mathrm{TCDD})}\right)$ was calculated to be $60 \mathrm{pM}$ by fitting the dose-response data into a three parameter sigmoidal Hill curve using Sigma Plot (SPSS, Chicago, IL, USA). The minimal detection limit was $64 \mathrm{fg} /$ well with an intra CV of $5-10 \%$ and an inter CV of $10-20 \%$. The sample solvent controls (+/- $\left.\mathrm{EC}_{50(\mathrm{TCDD})}\right)$ consisted of sample solvent treated like the serum extract but without the extract, and the $\mathrm{EC}_{50 \text { (TCDD) }}$ was used as parallel positive control in each assay on each plate.

AhR agonistic effect (AhRag) was determined by exposure of the cells to serum extracts alone, and the competitive AhR effect (AhRcomp) was determined upon co-exposure with serum extract and $60 \mathrm{pM}$ TCDD $\left(\mathrm{EC}_{50}\right)$. The AhRCALUX assay can be described shortly as follows: The Hepa1.12cR cells were seeded into sterile 96-well white CulturPlate $^{\mathrm{TM}}$ (Packard Instruments) at $6 \times 10^{4}$ cells per well and cultured in supplemented $\alpha$-MEM containing $400 \mu \mathrm{g} / \mathrm{ml}$ geneticin (G418, Sigma-Aldrich) at $37^{\circ} \mathrm{C}, 5 \%$ $\mathrm{CO}_{2}$ in $95 \%$ humidified air for $24 \mathrm{~h}$, allowing cells to reach $90-100 \%$ confluence. Then media were removed and the cells were in parallel exposed to the serum extract, serum extract plus 60 pM TCDD, and sample solvent con- trols in a total volume of $100 \mu$ l per well in triplicate. After exposure for $4 \mathrm{~h}$, cells were washed with phosphate-buffered saline (PBS, pH 7.4) followed by addition of cell lyses buffer. Luciferase activity and cell protein were determined as described [33]. The luciferase activity was expressed in relative light units per microgram protein (RLUs/ $\mu$ g protein). The average intra-sample CV was $11 \%$ and the inter CV of solvent control was $19 \%$.

No cell toxicity on Hepa1.12cR cells was determined by the CellTiter 96 assay from Promega (Madison. WI, US) [33] after exposure to the tested serum extract.

The determinations of AhR activity was in good inter-lab precision, as determined from the results of interlaboratory comparison program (Second round of interlaboratory comparison of dioxin-like compounds in food using bioassay, Orebro, Sweden).

\section{4. Calculation and statistical analysis}

In the independent assays the activity differences between the triple serum extract determinations and their respective solvent controls (\% agonistic, \% antagonistic and \% additive/synergistic, Table 2) were evaluated using the Student t-test (Microsoft Excel). The data was given as RLU per $\mathrm{ml}$ serum and the value of the solvent controls was 6.67 RLU/ml serum.

The CALUX-based AhR-TEQs values of serum extract were obtained by interpolation of AhRag values onto the TCDD dose-response sigmodal Hill curve (see additional file 1: TCDD dose-response curve for AhR mediated luciferase activity). Only the AhRag values being significantly higher than the solvent control and in the linear range of the TCDD dose-response curve were used to calculate AhR-TEQ.

The natural logarithmic transformed AhR-mediated activities and markers of POPs improved the normality (checked by Q-Q plots) and homogeneity of variance, and the statistical analysis was performed on the ln-transformed data. The comparisons of means between the different variables (POP markers, AhRag, AhR-TEQ and AhRcomp) were performed with One-way ANOVA test. When ANOVA showed statistical significant difference complementary multiple comparison ad hoc tests was performed. Test for equal variances was performed with Levene's test. The least-significant difference (LSD) test was used if the variables have equal variance; otherwise Dunett T3 test was used.

Bivariate correlations were evaluated by Spearman's rank correlation test. The overall association between the POP markers and AhR-mediated activities across the study groups (combined data) was assessed by comparing the 
Table 2: AhR-mediated serum activities, TCDD equivalents and lipid adjusted POP markers in serum

\begin{tabular}{|c|c|c|c|c|c|c|}
\hline & & Greenland & Warsaw & Sweden & Kharkiv & All \\
\hline \multirow{5}{*}{$\begin{array}{c}\text { AhRag*l }(\mathrm{RLU} / \mathrm{ml} \\
\text { serum })\end{array}$} & $N$ & 75 & 99 & 78 & 86 & 338 \\
\hline & Median & 24 & 34 & 33 & 26 & 29 \\
\hline & Min & 6.6 & 11 & 8.0 & 8.8 & 6.6 \\
\hline & Max & 257 & 118 & 103 & 56 & 257 \\
\hline & $\%$ agonist & 92 & 100 & 95 & 100 & 97 \\
\hline \multirow{4}{*}{$\begin{array}{c}\text { AhR-TEQ } \\
\text { lipid) }\end{array}$} & $N$ & 70 & 99 & 76 & 80 & 325 \\
\hline & Median & 197 & 312 & 428 & 337 & 310 \\
\hline & Min & 38 & 72 & 104 & 110 & 38 \\
\hline & Max & 1188 & 1054 & $126 \mid$ & 781 & $126 \mid$ \\
\hline \multirow{6}{*}{$\begin{array}{c}\text { AhRcomp*3 } \\
\text { (RLU/ml serum) }\end{array}$} & $N$ & 75 & 99 & 78 & 86 & 339 \\
\hline & Median & 8.3 & 6.4 & 6.2 & 5.5 & 6.8 \\
\hline & Min & 3.9 & 3.2 & 1.6 & 1.5 & 1.5 \\
\hline & Max & 16 & 9.1 & 10 & 11 & 16 \\
\hline & $\%$ add/syn & 41 & 3.0 & 6.4 & 18 & 16 \\
\hline & \%antagonist & 2.7 & 8.0 & 12 & 34 & 14 \\
\hline \multirow{4}{*}{$\begin{array}{c}\text { CB-I53 (ng/g } \\
\text { lipid) }\end{array}$} & $N$ & 74 & 100 & 98 & 82 & 355 \\
\hline & Median & 220 & 16 & 210 & 47 & 78 \\
\hline & Min & 5.1 & 3.3 & 41 & 5.5 & 3.3 \\
\hline & Max & 5500 & 130 & 1500 & 200 & 5500 \\
\hline \multirow{4}{*}{$\begin{array}{c}\text { p,p'-DDE (ng/g } \\
\text { lipid) }\end{array}$} & $\mathrm{N}$ & 74 & 100 & 98 & 82 & 355 \\
\hline & Median & 630 & 570 & 240 & 880 & 560 \\
\hline & Min & 66 & 240 & 55 & 320 & 55 \\
\hline & Max & 13000 & 2100 & 2300 & 12000 & 13000 \\
\hline
\end{tabular}

*I: AhRag: AhR activity of serum extract alone determined as the relative luciferase activity (RLU) per $\mathrm{ml}$ serum; Solvent background control $=6.67$ $\mathrm{RLU} / \mathrm{ml}$ serum. The \% agonistic indicates the \% of samples eliciting a significant increase in AhR activity compared to the solvent control. $* 2$ AhRTEQ (TCDD equivalents): The samples eliciting significantly agonistic activity was calculated by interpolation to the TCDD dose-response curve using the Sigmaplot program, given as pg/g serum lipid. *3 AhRcomp: AhR competitive activity of serum extract + 60 pM TCDD (EC 50 ) given as RLU/ $\mathrm{ml}$ serum. $\mathrm{EC}_{50}$ solvent control $=6.67 \mathrm{RLU} / \mathrm{ml}$ serum; \% add/syn and \%antagonistic indicates the \% of samples responding with a further increase or decrease of the $\mathrm{EC}_{50(\mathrm{TCDD})}$ induced activity, respectively.

regression lines for each study group by using multiple regression analysis.

Up to date few studies on dioxin-like activities in human serum have been reported [34-37], and thus the knowledge is limited about which dietary or other life-style determinants might affect serum dioxin-like activity. Our hypothesis is that potential determinants of POP bioaccumulation might also be potential determinants for serum dioxin-like activity. Guided by the literature [38] and also from the assessment of the main Inuendo study populations $[26,27]$, age and seafood are known determinants affecting the POP serum level. Moreover, lifestyle characteristics (Table 1) were evaluated as potential determinants of AhRag, AhR-TEQ and AhRcomp levels. Multiple linear regression model was used to assess the impact of the POP biomarkers on AhRag, AhR-TEQ and AhRcomp. The impact of potential confounders were evaluated by entering blocks of variables together with either CB-153 or $p, p^{\prime}$-DDE as follows: in the first step, age and seafood intake were included in the model, and in the second step additionally smoking status, BMI, coffee intake and alcohol consumption were included in the model. Due to many missing values on the potential confounders the number of available observations in the confounder analyses are much smaller than in the unadjusted analysis on the full dataset (full dataset: $\mathrm{n}=338$, first step of confounders: $\mathrm{n}=232$, second step: $\mathrm{n}=164$ ). A reduction of the number of observations with more than $50 \%$ might introduce serious selection problems, and hence the confounder analyses might lack greater validity.

The AhR activities were tested in protein free serum extract, which may still contain endogenous steroids, thus testosterone (total and free) and estradiol [39] were further included in the linear regression model on the combined study group data.

The inter-population variations in POP markers, AhRag, AhR-TEQ and AhRcomp serum level were also assessed by 
linear regression models. In these models age was considered as a potential confounder to make age-adjusted comparisons.

The statistical analysis was performed on SPSS 13.0 (SPSS Inc. Chicago, IL, USA). The statistical significant level was set to $\mathrm{p} \leq 0.05$.

\section{Results}

\section{I. The basic characteristics and serum levels of CB-I53} and $p, p$ '-DDE

The distributions of demographic and lifestyle factors (Table 1) and the serum CB-153 and p,p'-DDE levels (Table 2) of the 338 adult males in this study were similar to that of the main Inuendo study population [26,27]. The Greenland and Swedish groups elicited higher CB153 level than the Kharkiv and Warsaw group, and the level of CB-153 of Warsaw group was significantly lower than the other groups (Table 2 and see additional file 2A: Multiple comparisons of variables). The $p, p^{\prime}$-DDE level in Kharkiv was the highest, followed by Greenland and Warsaw, and the significant lowest level was found for the Swedish fishermen (Table 2 and see additional file 2A: Multiple comparisons of variables). As for the main study [27], age adjustment did not change the pattern of difference for the POP markers between the study groups.

A higher correlation between serum concentration of CB153 and $p, p^{\prime}$-DDE was found for the Greenlandic $\left(r_{s}=\right.$ $0.94, \mathrm{p}<0.001)$ and Swedish groups $\left(\mathrm{r}_{\mathrm{s}}=0.75, \mathrm{p}<0.001\right)$, and lower correlations were observed for the Kharkiv $\left(\mathrm{r}_{\mathrm{s}}=\right.$ $0.45, \mathrm{p}<0.001)$ and the Warsaw $\left(\mathrm{r}_{\mathrm{s}}=0.27, \mathrm{p}<0.01\right)$ study groups (see additional file 2B: Spearman's correlation between serum AhR activities and the levels of CB-153 and p.p'-DDE).

\subsection{Agonistic and competitive AhR activity in the four study groups}

Almost all serum samples (97\%) showed AhRag activity significantly higher than the solvent control (Table 2). The AhRag activity and AhR-TEQ differed significantly among the study groups (Table 2 and see additional file 2A: Multiple comparisons of variables): the Greenland and Kharkiv groups had lower AhRag medians than Sweden and Warsaw groups (Fig. $1 \mathrm{~A}$ and see additional file 2A: Multiple comparison of variables), and the AhR-TEQ median level of Greenland group was significantly lower than that of the European study groups (Table 2, Fig 1B and see additional file 2A: Multiple comparisons of variables).

The Greenlandic AhRcomp activity, eliciting the highest incidence (41\%) of sample with further increasing TCDD induced AhR activity, was significantly higher than for the European groups (Table 2, Fig. 1C and see additional file
2A: Multiple comparisons of variables), whereas the Kharkiv group showed the highest frequency of sample with antagonistic effect on TCDD induced AhR activity (Table 2).

Compared to the crude data, the pattern of differences of AhRag, AhR-TEQ and AhRcomp between the study groups did not change after adjustment for age (data not shown).

\subsection{Associations between AhRag, AhR-TEQ, AhRcomp and the POP markers}

Significant inverse correlation $\left(\mathrm{r}_{\mathrm{s}}=-0.30, \mathrm{p}<0.01\right)$ between AhRcomp and CB-153 was observed for the Kharkiv group (Fig. 2 and see additional file 2B: Spearman's correlation between serum AhR activities and the levels of CB-153 and p.p'-DDE). Neither AhRag nor AhRTEQ was found to correlate to the two POP markers for any of the study groups (see additional file 2B: Spearman's correlation between serum AhR activities and the levels of CB-153 and p.p'-DDE).

Adjustment for potential confounders in the multiple regression models did not change the strength of association between exposure variables (POP markers) and outcome variables (AhR-mediate activities) when compared with the unadjusted models. Further adjustment for endogenous testosterone and estradiol neither changed this pattern (data not shown).

\section{4. Multiple regressions of AhR-mediated activities on POP markers across the study groups}

Scatter plots of AhR-mediated activities against POP markers for the study groups are shown in Figure 3. Multiple regression analysis showed homogeneity of associations between CB-153 or $p, p^{\prime}$-DDE and AhRag and AhRTEQ as well as AhRcomp and $p, p^{\prime}$-DDE across the study groups (Table 3), i.e. parallel regression lines among study groups. Furthermore, a model with parallel regression lines showed a significant differences between the intercepts of the study groups (Table 3), thus the differences in AhRag/AhR-TEQ/AhRcomp between study groups still exist after adjustment for CB-153 or $p, p^{\prime}$-DDE. However, heterogenetic associations between serum CB-153 and the AhRcomp across the study groups were found (Table 3). Thus the difference of AhRcomp between the study groups was correlated to the CB-153 level, which supports the negative correlation between AhRcomp and CB-153 for the Kharkiv group.

\section{Discussion}

In the present study we measured the integrated AhR mediated activity in the lipophilic serum fraction containing POPs using the mechanistically based AhR-CALUX bioassay. No consistent correlation between the POP markers (CB-153 and $p, p^{\prime}$-DDE) and AhR mediated activ- 
A

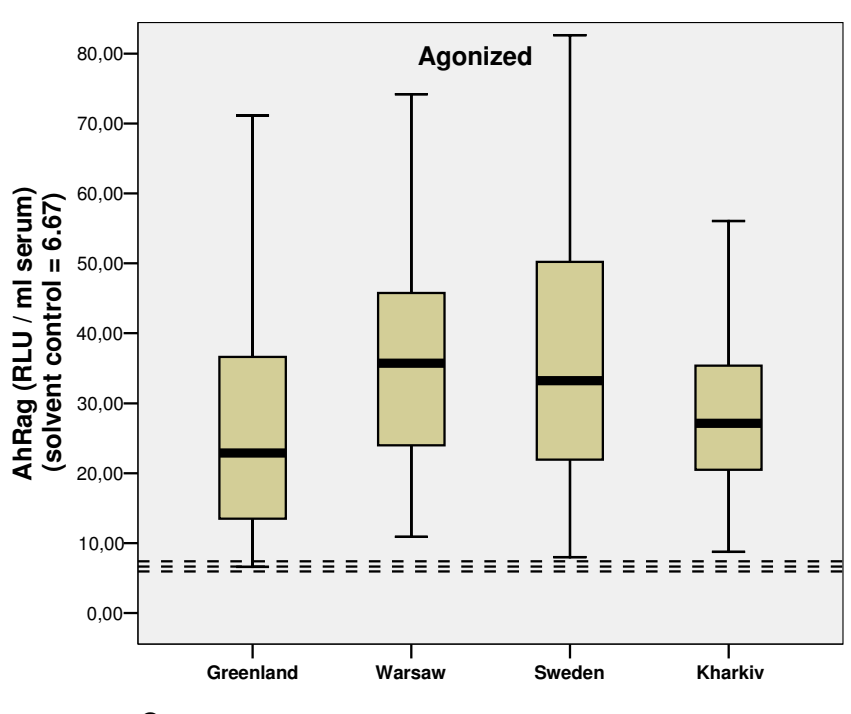

C

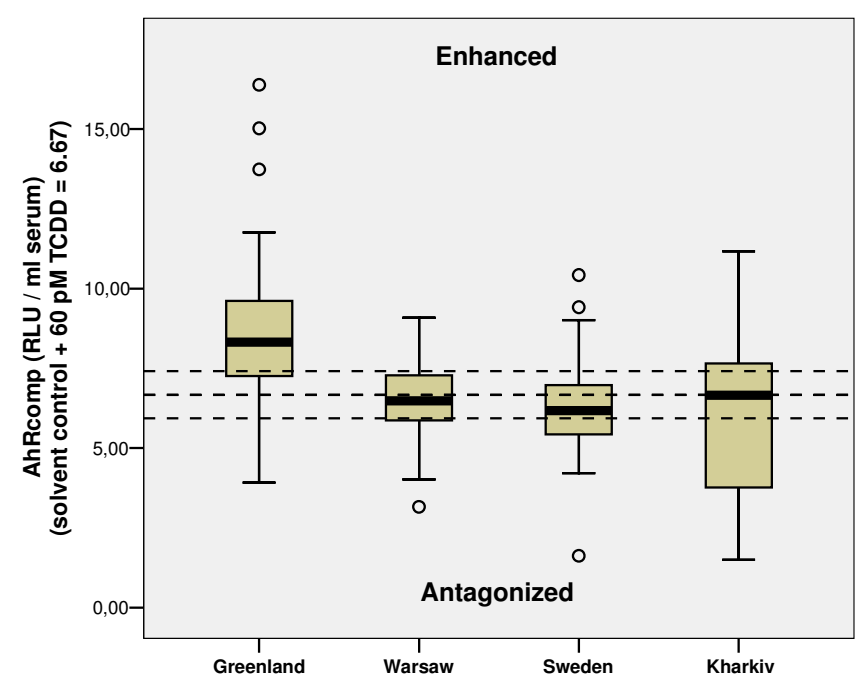

B

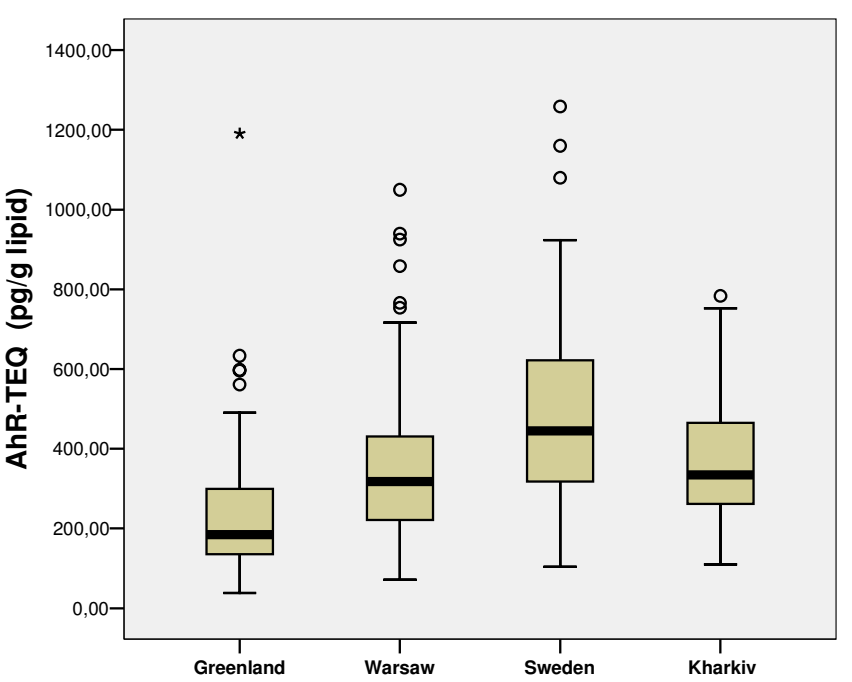

Figure I

AhR-CALUX activities of the study groups. (A) Agonistic activity of serum extracts alone (AhRag), (B) AhR-TEQ (AhRCALUX- TCDD toxic equivalent) and (C) competitive AhR activity upon cotreatment with 60pMTCDD (EC Fo ) and serum extract (AhRcomp). For the AhRag the outliers ranging from 86.01 to III I.28 RLU/ml serum and extreme values (I I7.87 257.13 RLU/ml serum) are not shown. The reference lines of the respective solvent controls \pm SD $(6.67 \pm 0.74)$ are given as dashed lines.

ities were found. However, in accordance with its high incidence of antagonistic AhRcomp activity, a negative correlation between AhRcomp and CB-153 was found in Kharkiv group. This finding is supported by earlier reports that CB-153 and associated compounds antagonized TCDD induced AhR action [40,41], as well as observation in our laboratory (Long and Bonefeld-Jorgensen, manuscript in prep.).
The study showed that $97 \%$ of the serum samples across the study groups elicited significant agonistic AhR activity. The median of AhRag activity in the Warsaw and Swedish groups reached higher level compared to the Kharkiv and the Greenlandic groups. Moreover, the median levels of AhR-TEQ of the European study groups were significantly higher than that of the Greenlandic Inuit's having high burden of both CB-153 and p,p'-DDE. We do not exactly 


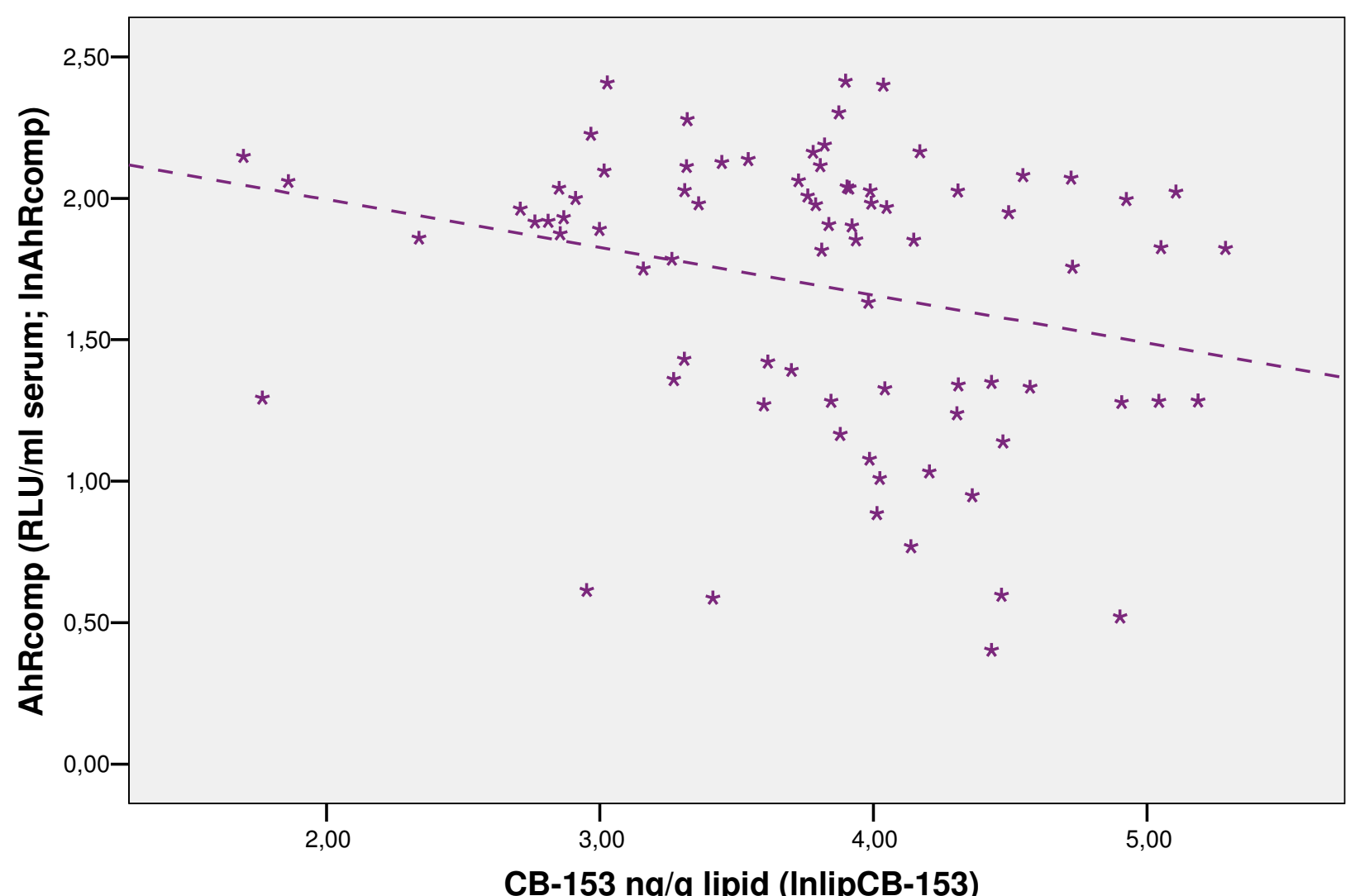

Figure 2

The relationship between AhRcomp activity and CB-I53 for the Kharkiv group. Scatterplot of correlation between serum AhRcomp and CB-I53. For definitions of AhRcomp see legend to Table 2. Ln-transformed data was used. RLU: relative luciferase units.

know the dietary habit of the Warsaw study group. How- ever, relatively high level of dioxins and DLCs were

Table 3: Multiple regressions of the combined study groups

\begin{tabular}{|c|c|c|c|c|}
\hline Response variable & $\begin{array}{l}\text { Homogeneity of slope (P } \\
\text { value) }\end{array}$ & $\begin{array}{c}\text { Common slope, Estimate } \\
\text { (SE), p value }\end{array}$ & $\begin{array}{c}\text { Common intercept ( } \mathrm{p} \\
\text { value) }\end{array}$ & Adjusted $\mathrm{R}$ square \\
\hline \multicolumn{5}{|l|}{ AhRag $(n=327)$} \\
\hline CB- $153^{\circ}$ & 0.95 & $-0.03(0.04), 0.43$ & 0.001 & 0.05 \\
\hline$p, p^{\prime}-\mathrm{DDE}$ & 0.28 & $-0.02(0.05), 0.70$ & 0.001 & 0.05 \\
\hline \multicolumn{5}{|c|}{ AhR-TEQ $(n=324)$} \\
\hline CB-I53 & 0.54 & $0.1 \mathrm{I}(0.04), 0.77$ & $<0.001$ & 0.20 \\
\hline$p, p^{\prime}-\mathrm{DDE}$ & 0.99 & $0.08(0.05), 0.07$ & $<0.001$ & 0.20 \\
\hline \multicolumn{5}{|c|}{ AhRcomp $(n=327)$} \\
\hline CB-153 & 0.01 & $-*$ & $-*$ & $-*$ \\
\hline$p, p^{\prime}-\mathrm{DDE}$ & 0.80 & $-0.03(0.03), 0.24$ & $<0.001$ & 0.18 \\
\hline
\end{tabular}

Both AhR activities and POP markers are In transformed. Homogeneity of slope: test for homogeneity of association between exposure variables and outcome variables across the study group ( $p>0.05$, accept the hypotheses of homogeneity of slope). Common slope: the estimated common slope across study groups assuming homogeneity ( $p>0.05$, accept the hypotheses that slope equals to zero). Common intercept: test of a common intercept across study groups assuming a common slope ( $p>0.05$, accept the hypotheses having common intercept across the study groups). Adjusted R square assumes a common slope. *: Since heterogeneity of slope exists between CB-I53 and AhRcomp across the study groups, i.e. there were country differences in the association of CB-I53 and AhRcomp, no further evaluation was performed. 
A

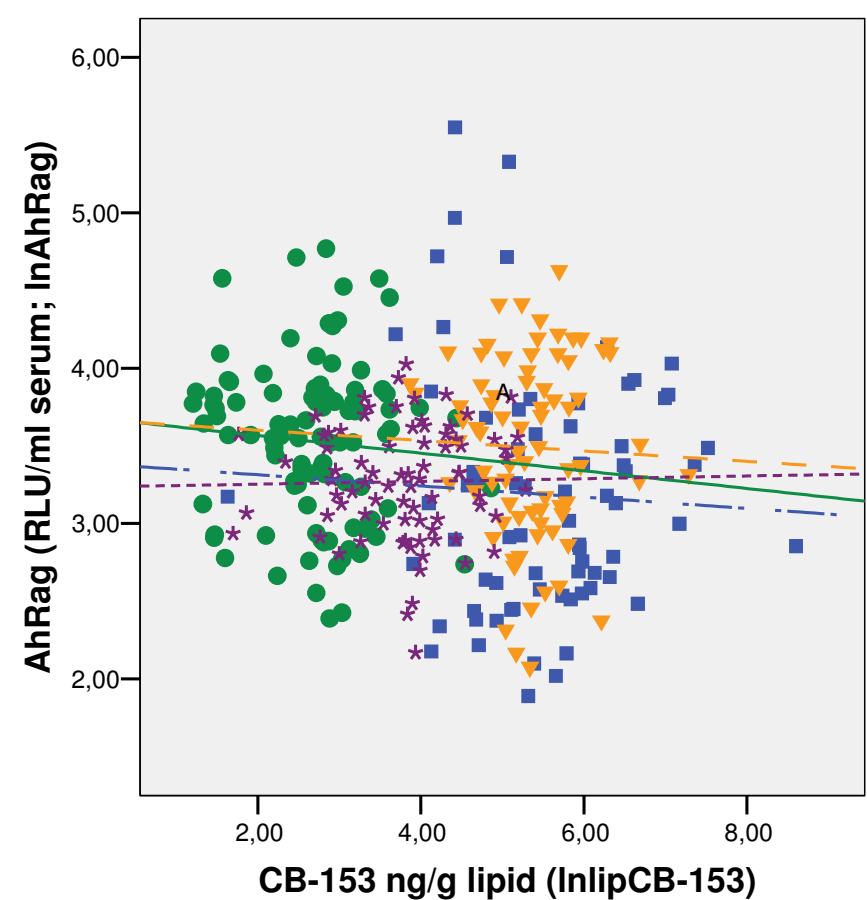

C

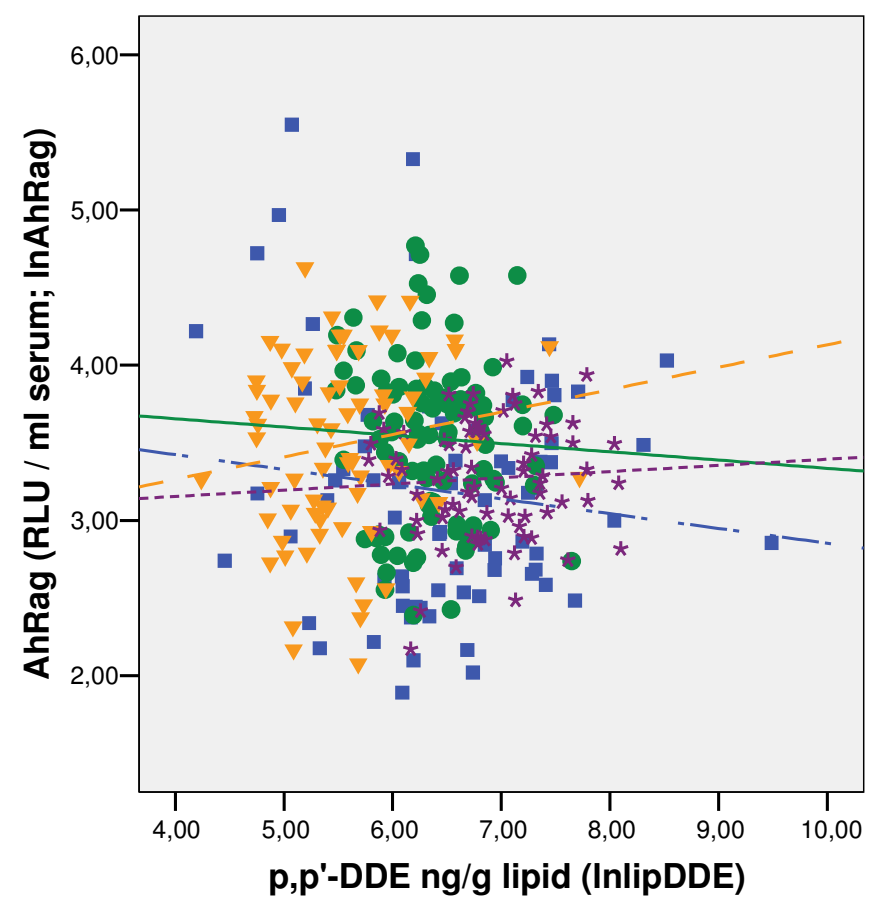

B
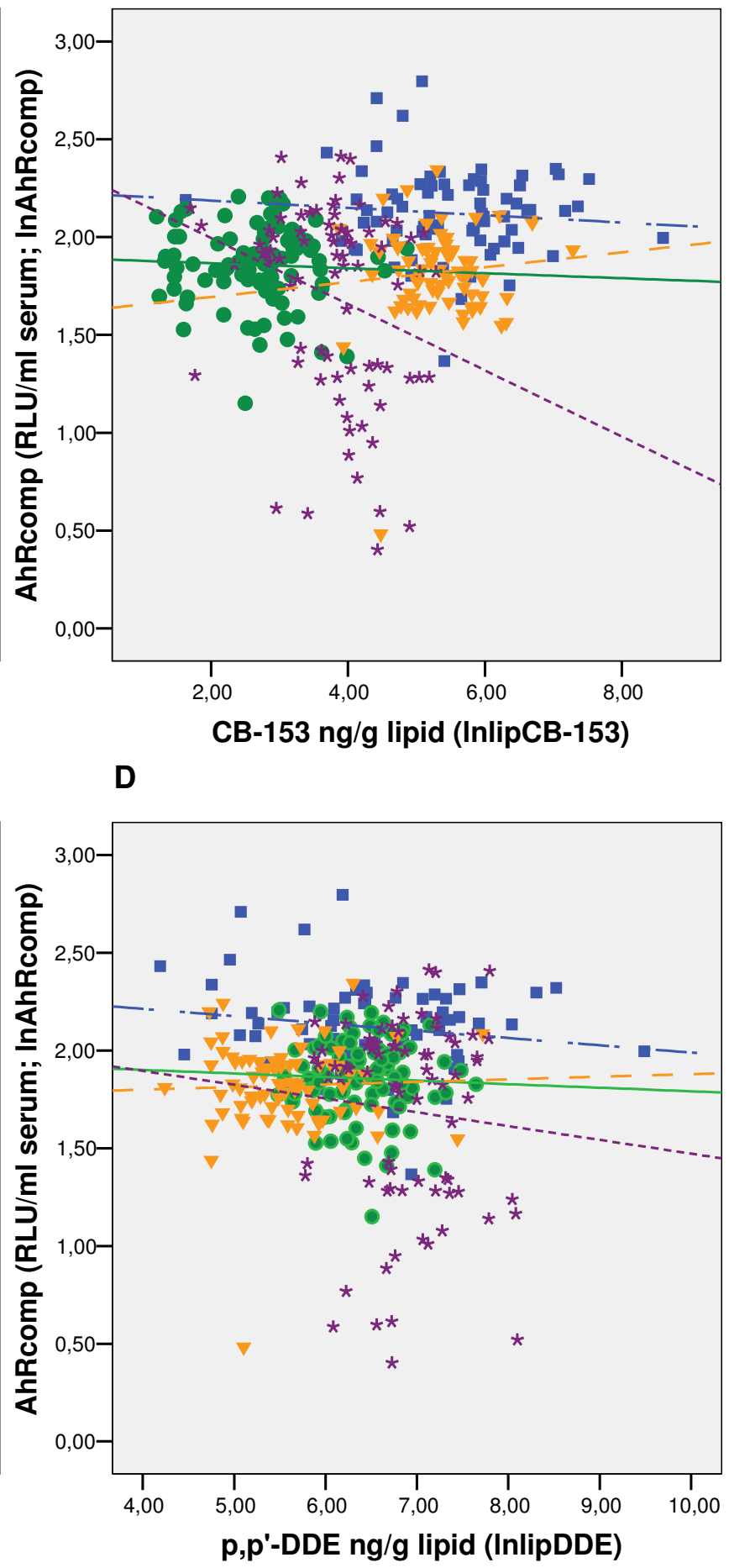

Figure 3

The association between AhR activity and POP markers in the study groups. The AhR activities are given for the four country based study groups as relation between (A) AhRag and CB-I53, (B) AhRcomp and CB-I53, (C) AhRag and p,p'DDE, (D) AhRcomp and p,p'-DDE. Ln-transformed data was used. For the definition of AhRag and AhRcomp, see the legend to Table 2. RLU: relative luciferase units. Greenland: $-\cdots-$; Warsaw: $\bullet$ 
reported to be produced and emitted to the Polish environment $[42,43]$. The relatively higher AhRag and AhRTEQ in the Swedish study group may be caused by high exposure to dioxins and/or dioxin-like PCBs (DL-PCBs) [8].

Except for a recent study of Slovakia males [44], the AhRTEQ in the present study was relatively higher (2 8 fold) than other similar studies [35,37], which can be related to the difference in exposure time ( 4 hours versus 24 hours). During the optimal exposure time $(4 \mathrm{~h})$ of Hepa1.12cR cell line used in this study $[45,46]$, other active compounds in the lipophilic serum fraction such as polycyclic aromatic hydrocarbons (PAHs), polybrominated biphenyls (PBBs), polyhalogenated naphthalenes may interact and activate the AhR in the CALUX- bioassay. In other studies e.g. using rat H4IIE cells, the labile AhR agonists in the serum such as some PAHs and other chemicals may be degraded or metabolized during the 24 hours of exposure resulting in a relatively lower AhR response [47]. PAHs elicite high AhR response after short exposure $[47,48]$, nevertheless, in the present study the PAHs level would be very low in the serum extract because the purification method was not built specifically for these molecules. We do not assume that the endogenous compounds play a major role in our AhR response data because fatty acids and other nonclassical AhR ligands may be removed from the crude extract in the cleanup procedure [24,32]. However, we can not exclude that some organic endogenous AhR inducers possibly passed through the purification columns and contribute to the AhR response [49]. Owing to the possible existence of cross-talk between AhR and ER and $\mathrm{AR}$, it can not be excluded whether the xenohormones and/or endogenous sex hormones (estradiol and testosterone) influence the observed AhR response. Although the influence is expected to be of minor importance since no correlation between the sex hormones and AhR-mediated activity across the study groups were found. The extract in this study contains most organochlorine compounds including organochlorine pesticides like hexachlorobenzene (HCB) that can contribute to the AhR response [50]. Future investigations are required to elucidate the profile of serum compounds contributing to the AhR-CALUX response. Possibly, the gender might also influence the lipid adjusted AhR-TEQ level since the participants in other studies were female $[35,36]$.

The differences in AhRag/AhRcomp activities among the study groups suggest that there are regional differences in profiles of POPs, PAHs and/or other lipophilic AhR activating compounds. The higher frequency of samples further increasing the TCDD induced AhR activity in Inuit's indicated the presence of compounds which can enhance the effect of the TCDD, the most potent AhR ligand. Considering the further increase of AhRcomp using the TCDD dose-response curve (see additional file 2: TCDD doseresponse curve for AhR mediated luciferase activity), the median AhR-TEQ determined in serum of the corresponding subgroup $(\mathrm{n}=180)$ was calculated to be $1.3 \mathrm{ng} / \mathrm{g}$ lipid, suggesting an increasing risk from DLCs when a strong AhR ligand exists simultaneously in the body.

Studies of Inuit populations in Canada support in general the use of CB-153 as a surrogate marker of exposure to non-DL-PCBs present in the Arctic food-chain [51]. However, the level of coplanar and non-coplanar PCBs was shown to differ between Canadian Inuits and Caucasian $[32,52]$. For non-occupational exposed Inuit populations in the Arctic Quebec the ratio between coplanar PCBs (e.g. CB-126 or CB-169) and the non-coplanar PCB (e.g. CB153 ) of Inuits was lower than that of the Caucasian reference group [52]. Moreover, DL-PCBs contributed to a larger extent to the chemical calculated TEQ than PCDD and PCDFs, with the mono-ortho coplanar CB-118 as major contributor for the total toxicity [52]. Similar difference may also exist for the populations included in this study, supporting the higher AhRag or AhR-TEQ level of Europeans.

Previously, CB-153 was reported to be highly correlated with calculated chemical-derived total TEQs and/or PCDD/PCDFs TEQs and/or non-ortho PCBs TEQs [29]. It should be noted that the chemical derived TEQ was calculated according to analytical chemistry data of some congeners under the assumption of additivity. Even though additive effects of PCDDs/PCDFs/DL-PCBs are predominating, non-additive effects such as antagonism and synergism can apply to interactions between individual DLCs in a complex mixture [53]. The TEQ based on the AhRCALUX bioassay represents the integrated sum of dioxinlike activities including additive, synergistic and antagonistic effect. Few epidemiology studies have reported analysis of association between di-ortho PCB (including CB153 ) and CALUX-TEQ, and the results were contradictory. A positive correlation was reported by Pauwels et al [35]. However, a recent report of the potential of the CALUX bioassay to estimate TEQ in plasma of Italian women with background exposure to dioxin and DLCs showed no significant correlation between CALUX-TEQ and the sum of four major PCB congeners (CB-118, CB-138, CB-153, CB180) [36]. Similar result was reported in a Belgium study [34]. The contradictory results may be related to the differences in study design, sample selection (gender and age of subjects, serum or plasma), composition and concentrations of bio-accumulated compounds in the blood and/or different sample extraction methods used in the CALUX bioassay as discussed $[36,49,54]$. Moreover, an important part of dioxin-like activity is elicited especially by PCDD/ Fs when their concentration is high in the sample [55]. One can find some correlations between PCB levels and 
dioxin-like activity only in the case that the concentrations of PCDD/Fs are low or comparable in different cohorts $[34,56]$.

\section{Conclusion}

$97 \%$ of analyzed samples elicited significant agonistic AhR induced activity. The level of AhR mediated activities differed among the study groups. European groups elicited higher AhR-TEQ than the Greenland Inuits, suggesting a higher exposure to DLCs. In addition, dietary habits/ life style factors and the genetic difference between Inuits and Caucasians [57] may also be taken into account.

No consistent significant correlation between CB-153 and $p, p$-DDE and AhR activities was observed and these two selected POP markers cannot alone predict the contribution of POPs, PAHs, and other lipophilic xenobitics to serum dioxin-like activity. Other more sensitive and specific tentative markers such as DL-PCBs (e.g. the monoortho congener CB-118 and CB-156) should be included in future epidemiology studies.

Since some less persistent compounds might contribute to the AhR-CALUX response due to the selected fractionation technique and that in vitro AhR-CALUX detects the overall dioxin-like response, it is not clear which compounds contribute to the observed dioxin-like activity. Thus the serum dioxin-like activity determined in this study must be interpreted as an independent parameter, complementary to chemical data. It should be kept in mind that the AhR-CALUX bioassay is not a substitute of actual chemical analysis by GC-MS techniques but provide biologically relevant results and normally is utilized as first tier screening tool followed by the chemical analysis to identify specific response compounds [24]. AhRCALUX bioassay provides an overall biological response/ potency of mixture, whereas chemical analysis provides the concentration of specific compounds in the mixture.

\section{Abbreviations \\ PCDDs/PCDFs polychlorinated dibenzo-p-dioxins/ furans}

PCBs polychlorinated biphenyls

DDT 2,2-bis(p-chlorophenyl)-1,1,1-trichloroethane

POPs persistent organochlorine pollutants

CB-153 2,2',4,4',5,5'-hexachlorobiphenyl

$\boldsymbol{p}, \boldsymbol{p}$ '-DDE 1,1-dichloro-2.2-bis (p-chlorophenyl)-ethylene

TCDD 2,3,7,8-tetrachlorodibenzo-p-dioxin
AhR aryl hydrocarbon receptor

TEQs TCDD toxic equivalents

CALUX Chemical activated luciferase gene expression

TEFs Toxic Equivalency Factors

DLCs Dioxin-like compounds

DL-PCBs dioxin-like PCBs

GC-MS gas chromatography mass spectrometry

AhRag agonistic AhR activity

AhRcomp competitive AhR activity

\section{Competing interests}

The author(s) declare that they have no competing interest

\section{Authors' contributions}

ML and ECB-J drafted the work and were the main responsible for design, performance, data evaluation and statistical analyses of the specific project; ML and BSA performed the mechanistic work; CL performed POP determinations in blood; JPB was main responsible for raising funding for the project. GT, HSP, VZ have been responsible for collecting blood samples and for obtaining the interview data. JPB, AG and LH initiated and designed the Inuedo project. JPB and GT coordinated the execution of project and GT had main responsibility for creating the joint database. All authors participated in the design of the study, comment on the draft and have read and approved the final manuscript. 


\section{Additional material}

\section{Additional file 1}

TCDD dose-response curve for AhR mediated luciferase activity. The 96-well plates containing Hepa1.12cR cells at 90-100\% confluence were incubated with TCDD at the indicated concentration for 4 hours. Luciferase activity in cell lysates were determined and corrected to cell protein. The data is expressed as the luciferase activity above solvent control which was set to 1 . Values represent the mean $\pm S . D$. $(n \geq 5)$.The $E C_{50}$ is the half maximum effect concentration.

Click here for file

[http://www.biomedcentral.com/content/supplementary/1476069X-5-14-S1.doc]

\section{Additional file 2A}

Multiple comparisons of variables. Multiple comparisons were performed on In-transformed data. The values given are $p$ values. B Spearman's correlation between serum AhR activities and the levels of CB-153 and $\mathrm{p}, \mathrm{p}$ '-DDE. Continuous data was used. Spearman's correlation data is given. For definition of AhRag, AhRcomp and AhR-TEQ see legend to Table 2. Statistical significant data is given in bold.

Click here for file

[http://www.biomedcentral.com/content/supplementary/1476069X-5-14-S2.doc]

\section{Acknowledgements}

We thank Jan K. Ludwicki from Warsaw and Anna Rignell-Hydbom from Sweden for collecting the blood samples and interview data. Thanks to all CMT group members: Inger Sørensen for technical assistance, Tanja Krüger, Philip S. Hjelmborg and Mandana Ghisari for scientific support, and thanks to Hélène Åkesson, Berit Holmskov, and Christina Held for performing chemical analyses in a skilful way. This study is part of the Project "INUENDO - Biopersistent organochlorines in diet and human fertility. Epidemiological studies of time to pregnancy and semen quality in Inuit and European populations", supported by The European Commission to the $5^{\text {th }}$ Framework Programme Quality of Life and Management of Living Resources, Key Action 4 on Environment and Health (Contract no. QLK4CT-200I-00202) and INTAS (contract no 200I-2005). http://www.inu endo.dk. The work was also funded by the Danish Environmental Protection Agency, the Swedish Research Council and the Swedish Council for Environment, Agricultural Sciences and Spatial Planning, and he Ukranian part grants from INTAS (project 012 2205).

\section{References}

I. Turusov V, Rakitsky V, Tomatis L: Dichlorodiphenyltrichloroethane (DDT): ubiquity, persistence, and risks. Environ Health Perspect 2002, I I0(2): 125-128.

2. Smith $D$ : Worldwide trends in DDT levels in human breast milk. Int J Epidemiol 1999, 28(2): I79-I88.

3. Van den Berg M, Birnbaum L, Bosveld AT, Brunstrom B, Cook P, Feeley M, Giesy JP, Hanberg A, Hasegawa R, Kennedy SW, Kubiak T, Larsen JC, van Leeuwen FX, Liem AK, Nolt C, Peterson RE, Poellinger L, Safe S, Schrenk D, Tillitt D, Tysklind M, Younes M, Waern F, Zacharewski T: Toxic equivalency factors (TEFs) for PCBs, PCDDs, PCDFs for humans and wildlife. Environ Health Perspect 1998, I06(I 2):775-792.

4. Safe S: Polychlorinated biphenyls (PCBs), dibenzo-p-dioxins (PCDDs), dibenzofurans (PCDFs), and related compounds: environmental and mechanistic considerations which support the development of toxic equivalency factors (TEFs). Crit Rev Toxicol 1990, 21(1):5।-88.

5. Bonefeld Jorgensen EC, Ayotte P: Toxicological properties of persistent organic pollutants and related health effects of concern for the arctic populations. AMAP Assessment 2002: Human Health in the Arctic 2003, chapter 6 :57-74.

6. Van Oostdam JC, Dewailly E, Gilman A, Hansen JC, Odland JO, Chashchin V, Berner J, Butler-Walker J, Lagerkvist BJ, Olafsdottir K, Soininen L, Bjerregard P, Klopov V, Weber JP: Circumpolar maternal blood contaminant survey, 1994-1997 organochlorine compounds. Sci Total Environ 2004, 330(I-3):55-70.

7. Rylander L, Hagmar L: Mortality and cancer incidence among women with a high consumption of fatty fish contaminated with persistent organochlorine compounds. Scand J Work Environ Health 1995, 21(6):419-426.

8. Svensson BG, Nilsson A, Jonsson E, Schutz A, Akesson B, Hagmar L: Fish consumption and exposure to persistent organochlorine compounds, mercury, selenium and methylamines among Swedish fishermen. Scand J Work Environ Health 1995, 21(2):96-105.

9. Czaja K, Ludwicki JK, Goralczyk K, Strucinski P: Organochlorine pesticides, HCB, and PCBs in human milk in Poland. Bull Environ Contam Toxicol 1997, 58(5):769-775.

10. Gladen BC, Monaghan SC, Lukyanova EM, Hulchiy OP, ShkyryakNyzhnyk ZA, Sericano JL, Little RE: Organochlorines in breast milk from two cities in Ukraine. Environ Health Perspect 1999, I07(6):459-462.

II. Steenland K, Bertazzi P, Baccarelli A, Kogevinas M: Dioxin revisited: developments since the 1997 IARC classification of dioxin as a human carcinogen. Environ Health Perspect 2004, I I 2(13): I 265- I 268.

12. Lindstrom G, Hooper K, Petreas M, Stephens R, Gilman A: Workshop on perinatal exposure to dioxin-like compounds. I. Summary. Environ Health Perspect 1995, 103 Suppl 2: I35- 142.

13. Rowlands JC, Gustafsson JA: Aryl hydrocarbon receptor-mediated signal transduction. Crit Rev Toxicol I997, 27(2): 109-134.

14. Safe S, Krishnan V: Cellular and molecular biology of aryl hydrocarbon (Ah) receptor-mediated gene expression. Arch Toxicol Suppl 1995, 17:99-1 I5.

15. Bonefeld-Jorgensen EC, Andersen HR, Rasmussen TH, Vinggaard AM: Effect of highly bioaccumulated polychlorinated biphenyl congeners on estrogen and androgen receptor activity. Toxicology 200I, I 58(3): I4I-I53.

16. Bonefeld-Jorgensen EC, Autrup H, Hansen JC: Effect of toxaphene on estrogen receptor functions in human breast cancer cells. Carcinogenesis 1997, 18(8):165I-1654.

17. Pocar P, Fischer B, Klonisch T, Hombach-Klonisch S: Molecular interactions of the aryl hydrocarbon receptor and its biological and toxicological relevance for reproduction. Reproduction 2005, I 29(4):379-389.

18. Amaral Mendes Jj: The endocrine disrupters: a major medical challenge. Food Chem Toxicol 2002, 40(6):78I-788.

19. Van Overmeire ICGCBDJCMDCWMDMSBWSSGL: Trace contamination with dioxin-like chemicals: evaluation of bioassay-based TEQ determination for hazard assessement and regulatory responses. Environmental Science \& Policy 200I, 4(6):345-357.

20. Aarts JM, Denison MS, Cox MA, Schalk MA, Garrison PM, Tullis K, de Haan LH, Brouwer A: Species-specific antagonism of Ah receptor action by $2,2^{\prime}, 5^{\prime}, 5^{\prime}$-tetrachloro- and 2,2',3,3'4,4'-hexachlorobiphenyl. Eur J Pharmacol 1995, 293(4):463-474.

21. Long M, Laier P, Vinggaard AM, Andersen HR, Lynggaard J, BonefeldJorgensen EC: Effects of currently used pesticides in the AhRCALUX assay: comparison between the human TVIOIL and the rat H4IIE cell line. Toxicology 2003, I 94(I-2):77-93.

22. Safe SH: Polychlorinated biphenyls (PCBs): environmental impact, biochemical and toxic responses, and implications for risk assessment. Crit Rev Toxicol 1994, 24(2):87-149.

23. Garrison PM, Tullis K, Aarts JM, Brouwer A, Giesy JP, Denison MS: Species-specific recombinant cell lines as bioassay systems for the detection of 2,3,7,8-tetrachlorodibenzo-p-dioxin-like chemicals. Fundam Appl Toxicol 1996, 30(2): 194-203.

24. Windal I, Denison MS, Birnbaum LS, Van Wouwe N, Baeyens W, Goeyens L: Chemically activated luciferase gene expression (CALUX) cell bioassay analysis for the estimation of dioxinlike activity: critical parameters of the CALUX procedure that impact assay results. Environ Sci Technol 2005, 39(19):7357-7364.

25. Inuendo: www.inuendo.dk The European Commission to the 5th Framework Programme Quality of Life and Manage- 
ment of Living Resources, Key Action 4 on Environment and Health (Contract no. QLK4-CT-200I-00202) and INTAS (contract no 200I-2005). Biopersistent organochlorines in diet and human fertility. Epidemiological studies of time to pregnancy and semen quality in Inuit and European populations.

26. Toft G, Axmon A, Giwercman A, Thulstrup A, Rignell-Hydbom A, Pedersen HS, Ludwicki J, Zvyesday V, Zhinchuk A, Spano M, Manicardi G, Bonefeld-Jorgensen E, Hagmar L, Bonde JP: Fertility in four regions spanning large contrasts in serum levels of widespread persistent organochlorines: a cross-sectional study. Environ Health 2005, 4(I):26.

27. Bo AG Jonsson LRCLARHAGGTHSPJKLKGVZMSDBECBJGCMJP$B L H$ : Inter-population variations in concentrations, determinants of and correlations between 2,2',4,4',5,5'hexachlorobiphenyl (CB-153) and I,I-dichloro-2,2-bis ( $p$ chlorophenyl)-ethylene (p,p'-DDE): a cross-sectional study of $316 \mathrm{I}$ men and women from Inuit and European populations. Environ Health 2005, 4(I):27.

28. Brouwer A, Ahlborg UG, Van den Berg M, Birnbaum LS, Boersma ER, Bosveld B, Denison MS, Gray LE, Hagmar L, Holene E, et al.: Functional aspects of developmental toxicity of polyhalogenated aromatic hydrocarbons in experimental animals and human infants. Eur J Pharmacol 1995, 293(I): I-40.

29. Longnecker MP, Ryan JJ, Gladen BC, Schecter AJ: Correlations among human plasma levels of dioxin-like compounds and polychlorinated biphenyls (PCBs) and implications for epidemiologic studies. Arch Environ Health 2000, 55(3): 195-200.

30. Sjodin A, Hagmar L, Klasson-Wehler E, Bjork J, Bergman A: Influence of the consumption of fatty Baltic Sea fish on plasma levels of halogenated environmental contaminants in Latvian and Swedish men. Environ Health Perspect 2000, I08(II): 1035-104|.

31. Rignell-Hydbom A, Rylander L, Giwercman A, Jonsson BA, Lindh C, Eleuteri P, Rescia M, Leter G, Cordelli E, Spano M, Hagmar L: Exposure to PCBs and p, $p^{\prime}-\mathrm{DDE}$ and human sperm chromatin integrity. Environ Health Perspect 2005, I I3(2): 175-179.

32. Butler Walker J, Seddon L, McMullen E, Houseman J, Tofflemire K, Corriveau A, Weber JP, Mills C, Smith S, Van Oostdam J: Organochlorine levels in maternal and umbilical cord blood plasma in Arctic Canada. Sci Total Environ 2003, 302(I-3):27-52.

33. Bonefeld-Jorgensen EC, Grunfeld HT, Gjermandsen IM: Effect of pesticides on estrogen receptor transactivation in vitro: a comparison of stable transfected MVLN and transient transfected MCF-7 cells. Mol Cell Endocrinol 2005, 244(I-2):20-30.

34. Covaci A, Koppen G, Van Cleuvenbergen R, Schepens P, Winneke G, van Larebeke N, Nelen V, Vlietinck R, Schoeters G: Persistent organochlorine pollutants in human serum of 50-65 years old women in the Flanders Environmental and Health Study (FLEHS). Part 2: Correlations among PCBs, PCDD/PCDFs and the use of predictive markers. Chemosphere 2002, 48(8):827-832.

35. Pauwels A, Cenijn PH, Schepens PJ, Brouwer A: Comparison of chemical-activated luciferase gene expression bioassay and gas chromatography for $P C B$ determination in human serum and follicular fluid. Environ Health Perspect 2000, I 08(6):553-557.

36. Warner M, Eskenazi B, Patterson DG, Clark G, Turner WE, Bonsignore L, Mocarelli P, Gerthoux PM: Dioxin-Like TEQ of women from the Seveso, Italy area by ID-HRGC/HRMS and CALUX. J Expo Anal Environ Epidemiol 2004

37. Ayotte P, Dewailly E, Lambert GH, Perkins SL, Poon R, Feeley M, Larochelle C, Pereg D: Biomarker measurements in a coastal fish-eating population environmentally exposed to organochlorines. Environ Health Perspect 2005, I I 3(10): | 3 |8-I324.

38. James RA, Hertz-Picciotto I, Willman E, Keller JA, Charles MJ: Determinants of serum polychlorinated biphenyls and organochlorine pesticides measured in women from the child health and development study cohort, 1963-1967. Environ Health Perspect 2002, I I0(7):617-624.

39. Giwercman Aleksander ARHGTLRLHCLHSPJKLMSVZMSGCMDBEBJJPBINUENDO: Reproductive Hormone Levels in Men Exposed to Persistent Organohalogen Polutants: A Study of Inuit and Three European Cohorts. Environmental Health Perspectives 2005, Submitted the 19th of December 2005:
40. Chen G, Bunce NJ: Interaction between halogenated aromatic compounds in the Ah receptor signal transduction pathway. Environ Toxicol 2004, 19(5):480-489.

4I. Suh J, Kang JS, Yang KH, Kaminski NE: Antagonism of aryl hydrocarbon receptor-dependent induction of CYPIAI and inhibition of IgM expression by di-ortho-substituted polychlorinated biphenyls. Toxicol Appl Pharmacol 2003, 187(I): II-2I.

42. Lassen C, Hansen E, Jensen AA, Olendrzynski K, Kolsut W, Zurek J, Kargulewicz I, Debski B, Skoskiewicz J, Holtzer M, Grochowalski A, Brante E, Poltimae H, Kallaste T, Kapturauskas J: Survey of dioxin sources in the Baltic Region (extended summary). Environ $\mathrm{Sci}$ Pollut Res Int 2003, 10(1):49-56.

43. Grochowalski A: PCDDs and PCDFs concentration in combustion gases and bottom ash from incineration of hospital wastes in Poland. Chemosphere 1998, 37(9-1 2):2279-2291.

44. Pliskova M, Vondracek J, Canton RF, Nera J, Kocan A, Petrik J, Trnovec T, Sanderson T, van den Berg M, Machala M: Impact of polychlorinated biphenyls contamination on estrogenic activity in human male serum. Environ Health Perspect 2005, I I 3( I0): 1277-I 284

45. Han D, Nagy SR, Denison MS: Comparison of recombinant cell bioassays for the detection of Ah receptor agonists. Biofactors 2004, 20(I):II-22

46. Ziccardi MH, Gardner IA, Denison MS: Development and modification of a recombinant cell bioassay to directly detect halogenated and polycyclic aromatic hydrocarbons in serum. Toxicol Sci 2000, 54(I): I83-193.

47. Jones JM, Anderson JW, Tukey RH: Using the metabolism of PAHs in a human cell line to characterize environmental samples. Environ Toxicol Pharmacol 2000, 8(2):119-126.

48. Machala M, Ciganek M, Blaha L, Minksova K, Vondrack J: Aryl hydrocarbon receptor-mediated and estrogenic activities of oxygenated polycyclic aromatic hydrocarbons and azaarenes originally identified in extracts of river sediments. Environ Toxicol Chem 200I, 20(I 2):2736-2743.

49. Van Wouwe N WIVHEGXCMACDNSABWDPESFOHGL: Validation of the CALUX bioassay for PCDD/F analyses in human blood plasma and comparison with GC-HRMS. Talanta 2004, 63:1157-II67.

50. Hahn ME, Goldstein JA, Linko P, Gasiewicz TA: Interaction of hexachlorobenzene with the receptor for 2,3,7,8-tetrachlorodibenzo-p-dioxin in vitro and in vivo. Evidence that hexachlorobenzene is a weak Ah receptor agonist. Arch Biochem Biophys 1989, 270(I):344-355.

5I. Muckle G, Ayotte P, Dewailly EE, Jacobson SW, Jacobson JL: Prenatal exposure of the northern Quebec Inuit infants to environmental contaminants. Environ Health Perspect 200I, 109(1 2): 129|-1299.

52. Dewailly E, Ryan J], Laliberte C, Bruneau S, Weber JP, Gingras S, Carrier G: Exposure of remote maritime populations to coplanar PCBs. Environ Health Perspect 1994, 102 Suppl I:205-209.

53. van den Berg M, Peterson RE, Schrenk D: Human risk assessment and TEFs. Food Addit Contam 2000, I 7(4):347-358.

54. Van Wouwe N WI: Importance of clean-up for comparison of TEQ-values obtained by CALUX and chemo-analysis. Talanta 2004, 63:1269-1272.

55. Focant JF, Pirard C, Thielen C, De Pauw E: Levels and profiles of PCDDs, PCDFs and CPCBs in Belgian breast milk. Estimation of infant intake. Chemosphere 2002, 48(8):763-770.

56. Koppen G, Covaci A, Van Cleuvenbergen R, Schepens P, Winneke G, Nelen V, van Larebeke N, Vlietinck R, Schoeters G: Persistent organochlorine pollutants in human serum of $50-65$ years old women in the Flanders Environmental and Health Study (FLEHS). Part I: Concentrations and regional differences. Chemosphere 2002, 48(8):8II-825.

57. de Maat MP, Bladbjerg EM, Johansen LG, de Knijff P, Gram J, Kluft C Jespersen J: DNA-polymorphisms and plasma levels of vascular disease risk factors in Greenland Inuit--is there a relation with the low risk of cardiovascular disease in the Inuit? Thromb Haemost 1999, 8 I(4):547-552. 